\title{
Lack of association between airflow limitation and recurrence of venous thromboembolism among cancer patients with pulmonary embolism
}

This article was published in the following Dove Press journal: International Journal of COPD

Sun Hye Shin,' Danbee Kang, ${ }^{2}$ Juhee Cho, ${ }^{2}$ Haseong Chang, ${ }^{3}$ Min Sun Kim, ${ }^{3}$ Su Yeon Lee, ${ }^{3}$ Hyun Lee,' Hojoong Kim,' Duk-Kyung Kim, ${ }^{3}$ Eun Kyoung Kim, ${ }^{3, *}$ Hye Yun Park ${ }^{1, *}$

'Division of Pulmonary and Critical Care Medicine, Department of Medicine, Samsung Medical Center, Sungkyunkwan University School of Medicine, Seoul, South Korea; ${ }^{2}$ Department of Clinical Research Design and Evaluation, SAIHST, Sungkyunkwan University, Seoul, South Korea; ${ }^{3}$ Division of Cardiology, Department of Medicine, Heart Vascular Stroke Institute, Samsung Medical Center, Sungkyunkwan University School of Medicine, Seoul, South Korea

*These authors contributed equally to this work

Correspondence: Hye Yun Park

Division of Pulmonary and Critical Care Medicine, Department of Medicine, Samsung Medical Center, Sungkyunkwan University School of Medicine, 8I Irwon-ro, Gangnam-gu, Seoul 0635I, South

Korea

$\mathrm{Tel}+82234103429$

Fax +82234103849

Email hyeyunpark@skku.edu

Eun Kyoung Kim

Division of Cardiology, Department of Medicine, Heart Vascular Stroke Institute, Samsung Medical Center, Sungkyunkwan University School of Medicine, 8 I Irwon-ro, Gangnam-gu, Seoul 0635I, South Korea

Tel +82234103419

Fax +82 234103849

Email ekbobi.kim@samsung.com
Background: COPD is a well-known risk factor for venous thromboembolism (VTE) development. However, recent data showed that it was not associated with VTE recurrence risk, which excluded cancer patients. This study investigated the association of airflow limitation and VTE recurrence in cancer patients with pulmonary embolism (PE).

Methods: This is a retrospective cohort study of cancer patients with newly diagnosed PE at a university hospital. PE was confirmed using contrast-enhanced computed tomography scan. Airflow limitation was defined as pre-bronchodilator forced expiratory volume in 1 second $\left(\mathrm{FEV}_{1}\right) /$ forced vital capacity $(\mathrm{FVC})<0.7$ within 2 years of PE diagnosis. VTE recurrence was defined as a composite of recurrence as PE or deep vein thrombosis or both.

Results: Among 401 cancer patients with newly diagnosed PE, spirometry-based airflow limitation was observed in $126(31.4 \%)$ patients. Half of the patients had lung cancer, which was more common in the group with airflow limitation $(65.1 \%$ vs $42.9 \%, p<0.001)$. Symptomatic PE was present in less than half $(45.4 \%)$ of the cases, and $62.6 \%$ of patients were treated for PE. During the median follow-up period of 9.7 months, VTE recurred in 49 (12.2\%) patients. Compared with patients without airflow limitation, those with airflow limitation did not have an increased risk of VTE recurrence in univariate or multivariate analyses (adjusted hazard ratio, 1.29 [95\% CI 0.68, 2.45]).

Conclusion: The presence of airflow limitation did not increase the risk of VTE recurrence in cancer patients with PE. Prospective studies are needed to validate this finding.

Keywords: chronic obstructive pulmonary disease, cancer, pulmonary embolism, recurrence, venous thromboembolism

\section{Introduction}

VTE is a common cardiovascular disease with an annual incidence from 104 to 183 per 100,000 person-years. ${ }^{1}$ It comprises DVT or PE or both. Acute PE is the most serious manifestation of VTE and results in high short-term mortality, chronic complications, and frequent recurrence. ${ }^{2-4}$ The cumulative incidence of VTE recurrence has been reported to reach $13 \%$ at 1 year, $23 \%$ at 5 years, and $30 \%$ at 10 years, and recurrent events can be fatal. ${ }^{4,5}$

COPD is a moderate risk factor for initial VTE and its prognosis. ${ }^{6,7}$ Several studies have shown that COPD patients have up to five times increased risk of PE or VTE compared with patients without COPD, and there is a significant association between VTE events and COPD severity. ${ }^{8-12}$ In addition, COPD patients with VTE have much higher mortality compared with COPD patients without VTE. ${ }^{13}$ Likewise, several studies based on PE and VTE registries suggested that COPD 
is an unfavorable prognostic factor for bleeding and mortality. ${ }^{2,714}$ However, VTE recurrence rates were similar between COPD patients and non-COPD patients during the 3-month follow-up period. ${ }^{14}$ Recent data from a prospective cohort study indicated that COPD did not increase the long-term risk of recurrent VTE. ${ }^{15}$ Although this study considered major provoking factors such as immobilization after surgery, use of estrogen-containing pills, or hormone replacement therapy, active cancer patients were not included. ${ }^{15}$ Cancer is a strong provoking factor of VTE development and outcomes, ${ }^{4,16-18}$ and the prevalence of cancer in COPD patients with PE was as high as $20 \%$ in a previous study. ${ }^{14} \mathrm{We}$ therefore investigated the association of spirometry-based airflow limitation with VTE recurrence among cancer patients with PE.

\section{Methods}

\section{Study population}

This is a retrospective cohort study conducted at Samsung Medical Center, Seoul, South Korea, between June 1, 2010, and December 31,2013. Among patients who were diagnosed with PE during the study period, those who were undergoing treatment or follow-up for pathologically confirmed cancer were identified. Patients with stump thrombosis, tumor emboli, and a history of PE were excluded.

\section{Measurements and data collection}

PE diagnosis was confirmed by contrast-enhanced chest CT, and two authors (SHS and HC) reviewed the CT images for evaluation of initial diagnosis, burden, and recurrence. Data regarding basic demographics, cancer diagnosis and treatment, symptoms and signs of PE, treatment for PE, date of VTE recurrence, last follow-up, or death were collected from electronic medical records. Regarding airflow limitation, spirometry performed within 2 years of PE diagnosis was considered. Spirometry was performed as recommended by the American Thoracic Society/European Respiratory Society using Vmax 22 (SensorMedics, Yorba Linda, CA, USA)..$^{19}$ Airflow limitation was defined as pre-bronchodilator $\mathrm{FEV}_{1} / \mathrm{FVC}<70 \%$.

The primary outcome was recurrence of VTE, defined as a composite of recurrence of PE or DVT or both. Diagnosis of recurrent $\mathrm{PE}$ was based on the $\mathrm{CT}$ scan, and the diagnosis of recurrent DVT was based on the duplex ultrasonography or CT venography. The institutional review board of Samsung Medical Center approved this study. Informed consent was waived due to the retrospective nature, and patient information was anonymized and de-identified prior to analysis.

\section{Statistical analysis}

Categorical variables were compared using the Chi-square test or Fisher's exact test, and continuous variables were compared using Student's $t$-test or Mann-Whitney $U$ test. Cox proportional hazard models were used to evaluate the impact of airflow limitation on VTE recurrence. For multivariate analyses, we used three models. The first model was adjusted for age, sex, BMI, and smoking status. The second model was further adjusted for metastatic disease and recent surgery. The third model was further adjusted for PE treatment. All tests were two sided, and $p$-value $<0.05$ was considered statistically significant. All analyses were performed using Stata (version 13.0; Stata Corporation, College Station, TX, USA).

\section{Results}

\section{Patient characteristics}

Among cancer patients with newly diagnosed PE during the study period, we identified 401 patients who underwent spirometry within 2 years (Figure 1); median time between spirometry and PE diagnosis was 92 days (IQR 47-231). Of the 401 patients, 126 (31.4\%) had airflow limitation. Patients with airflow limitation were older (66.3 years vs 62.0 years, $p<0.001)$, more likely to be male $(82.5 \%$ vs $52.4 \%, p<0.001)$, and more likely to be a current smoker $(66.7 \%$ vs $33.1 \%, p<0.001)$ as compared with those without airflow limitation. History of DVT and comorbidities were not different between the groups. Among cancer patients, about half (49.9\%) had lung cancer, which was significantly more common in patients with airflow limitation $(65.1 \%$ vs $42.9 \%, p<0.001)$. Although there were slightly more patients with metastatic disease in the group without airflow limitation, there were no differences between the two groups regarding recent surgery, ongoing chemotherapy, or radiotherapy (Table 1).

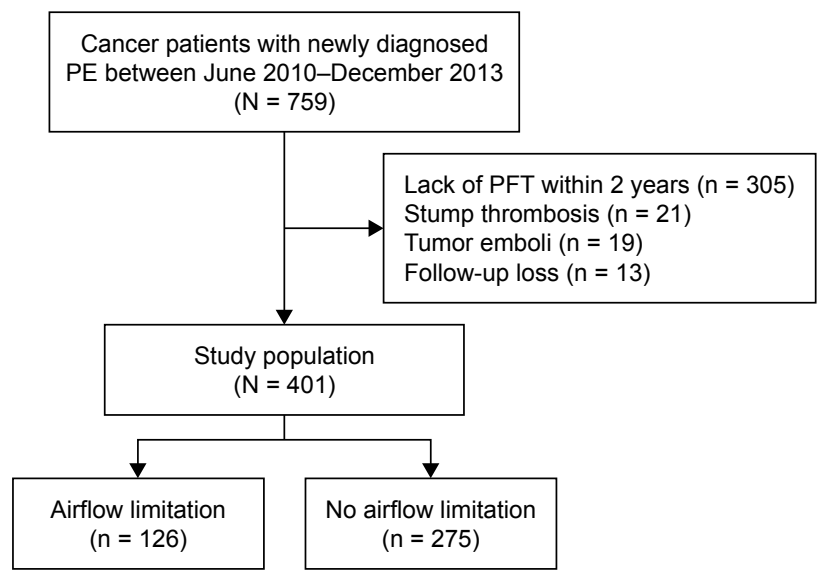

Figure I A consort diagram of the study population. Abbreviations: PE, pulmonary embolism; PFT, pulmonary function test. 
Table I Distribution of baseline characteristics in 40 I cancer patients with PE according to airflow limitation

\begin{tabular}{|c|c|c|c|}
\hline Characteristics & $\begin{array}{l}\text { No airflow } \\
\text { limitation } \\
(n=275)\end{array}$ & $\begin{array}{l}\text { Airflow } \\
\text { limitation } \\
(n=I 26)\end{array}$ & $p$-value \\
\hline Age (years) & $62.0(11.7)$ & $66.3(9.4)$ & $<0.001$ \\
\hline Sex, male & $144(52.4)$ & $104(82.5)$ & $<0.001$ \\
\hline Body mass index $\left(\mathrm{kg} / \mathrm{m}^{2}\right)$ & $23.5(3.6)$ & $23.4(3.1)$ & 0.712 \\
\hline Smoking & & & $<0.001$ \\
\hline Never & $170(6 \mid .8)$ & $32(25.4)$ & \\
\hline Former & $14(5.1)$ & $10(7.9)$ & \\
\hline Current & $91(33.1)$ & $84(66.7)$ & \\
\hline \multicolumn{4}{|l|}{ Comorbidity } \\
\hline Hypertension & $102(37.1)$ & $46(36.5)$ & 0.911 \\
\hline Diabetes & $53(19.3)$ & $16(12.7)$ & 0.105 \\
\hline Chronic kidney disease & $15(5.5)$ & $9(7.1)$ & 0.508 \\
\hline Previous DVT & $7(2.6)$ & $4(3.2)$ & 0.720 \\
\hline \multicolumn{4}{|l|}{ Cancer type } \\
\hline Lung & I I 8 (42.9) & $82(65.1)$ & $<0.001$ \\
\hline Colon & $38(13.8)$ & $10(7.9)$ & 0.092 \\
\hline Stomach & $20(7.3)$ & $3(2.4)$ & 0.051 \\
\hline Gynecologic & $19(6.9)$ & $\mathrm{I}(0.8)$ & 0.009 \\
\hline Esophagus & $8(2.9)$ & $7(5.6)$ & 0.195 \\
\hline Others & $72(26.2)$ & $23(18.3)$ & 0.083 \\
\hline Metastatic disease & $182(66.2)$ & $69(54.8)$ & 0.054 \\
\hline Surgery within 2 months & $53(19.3)$ & $26(20.6)$ & 0.750 \\
\hline Ongoing chemotherapy ${ }^{\ddagger}$ & $159(57.8)$ & $67(53.2)$ & 0.507 \\
\hline Ongoing/recent radiotherapy & $25(9.1)$ & $10(7.9)$ & 0.663 \\
\hline \multicolumn{4}{|l|}{ Pulmonary function } \\
\hline $\mathrm{FEV}_{1} / \mathrm{FVC}(\%)$ & $78.2(5.5)$ & $61.7(7.6)$ & $<0.001$ \\
\hline $\mathrm{FEV}_{1}$ (\% predicted) & $84.8(18.3)$ & $68.1(15.5)$ & $<0.001$ \\
\hline
\end{tabular}

Notes: Values are the mean (SD) or number (\%). \#More than 30 minutes of surgery time under general anesthesia. FPE developed during the chemotherapy or within one cycle of time after the last chemotherapy. ${ }^{\text {P }}$ E developed during the radiotherapy or within 13 weeks after the radiotherapy.

Abbreviations: DVT, deep vein thrombosis; $\mathrm{FEV}_{\text {, }}$, forced expiratory volume in I second; FVC, forced vital capacity; PE, pulmonary embolism.

\section{Clinical presentation, CT findings, and treatment of PE}

At the time of PE diagnosis, only $45.4 \%$ (182/401) of patients were symptomatic. Patients with airflow limitation were more likely to report dyspnea $(37.3 \%$ vs $26.6 \%, p=0.029)$ as compared with those without airflow limitation. Signs at PE diagnosis, such as tachycardia, hypoxia, and shock, and the burden of PE on chest CT were not found to be significantly different according to airflow limitation (Table 2). Of the 251 (62.6\%) patients who were treated for PE, only few were treated with embolectomy or thrombolysis along with anticoagulation treatment. Type and duration of anticoagulation did not differ significantly between the two groups (Table 3).

\section{VTE recurrence according to airflow limitation}

During the median follow-up period of 9.7 months (IQR 2.8-26.6), 49 (12.2\%) patients experienced VTE recurrence
Table 2 Clinical presentation and CT findings of PE in $40 \mathrm{I}$ cancer patients according to airflow limitation

\begin{tabular}{|c|c|c|c|}
\hline Clinical features & $\begin{array}{l}\text { No airflow } \\
\text { limitation } \\
(n=275)\end{array}$ & $\begin{array}{l}\text { Airflow } \\
\text { limitation } \\
(n=I 26)\end{array}$ & $p$-value \\
\hline $\begin{array}{l}\text { Symptoms at PE } \\
\text { diagnosis }\end{array}$ & $|2|(44.0)$ & $6 \mathrm{I}(48.4)$ & 0.225 \\
\hline Dyspnea & $73(26.6)$ & $47(37.3)$ & 0.029 \\
\hline Leg swelling/pain & $27(9.8)$ & $9(7.1)$ & 0.384 \\
\hline Chest pain & $14(5.1)$ & $3(2.4)$ & 0.211 \\
\hline Signs at PE diagnosis & $94(34.2)$ & $52(4 \mid .3)$ & $0.17 \mid$ \\
\hline Tachycardia & $75(27.3)$ & $49(38.9)$ & 0.065 \\
\hline Hypoxia & $53(19.3)$ & $29(23.0)$ & 0.668 \\
\hline Shock & II (4.0) & $6(4.8)$ & 0.892 \\
\hline \multicolumn{4}{|l|}{$C T$ finding } \\
\hline Bilateral PE & $119(43.3)$ & $54(42.9)$ & 0.938 \\
\hline Location & & & 0.276 \\
\hline Central & $53(19.3)$ & $33(26.2)$ & \\
\hline Lobar & $105(38.2)$ & $46(36.5)$ & \\
\hline $\begin{array}{l}\text { Distal segmental/ } \\
\text { subsegmental }\end{array}$ & $117(42.6)$ & $47(37.3)$ & \\
\hline
\end{tabular}

Note: Values are the number (\%).

Abbreviations: CT, computed tomography; PE, pulmonary embolism.

(14\% of patients with airflow limitation and $11 \%$ of those without airflow limitation). Among the patients with recurrent VTE, all (18/18) those with airflow limitation had PE (with or without DVT), whereas $19.4 \%(6 / 31)$ without airflow limitation had isolated DVT ( $p=0.073)$.

In the univariate analysis, airflow limitation was not associated with the risk of VTE recurrence (HR 1.31 [95\% CI $0.73,2.34]$ ) (Table 4 and Figure 2). The impact of airflow limitation on the risk of VTE recurrence remained insignificant after adjustment for patient-related characteristics (aHR 1.20 [95\% CI 0.64, 2.26]), for cancer-related characteristics

Table 3 Treatment for PE in $40 \mathrm{I}$ cancer patients according to airflow limitation

\begin{tabular}{|c|c|c|c|}
\hline Treatment features & $\begin{array}{l}\text { No airflow } \\
\text { limitation } \\
(n=275)\end{array}$ & $\begin{array}{l}\text { Airflow } \\
\text { limitation } \\
(n=126)\end{array}$ & $p$-value \\
\hline Observation without treatment & $103(37.5)$ & $47(37.3)$ & 0.977 \\
\hline \multicolumn{4}{|l|}{ Treatment ${ }^{\#}$} \\
\hline Embolectomy & $3(1.1)$ & 0 & 0.555 \\
\hline Thrombolysis & $\mathrm{I}(0.4)$ & $2(1.6)$ & 0.234 \\
\hline Anticoagulation & $17 \mid(62.2)$ & $79(62.7)$ & 0.921 \\
\hline Type of anticoagulation $n^{\ddagger}$ & & & 0.096 \\
\hline Warfarin & $105(6 \mid .4)$ & $59(74.7)$ & \\
\hline LMWH & $60(35.1)$ & $17(2 \mid .5)$ & \\
\hline NOAC & $6(3.5)$ & $3(3.8)$ & \\
\hline Anticoagulation duration (months) ${ }^{\ddagger}$ & $4.0(1.8-6.5)$ & $4.2(1.3-7.0)$ & 0.638 \\
\hline
\end{tabular}

Notes: Values are the number (\%) or median (interquartile range). "Data were overlapped. ${ }^{\ddagger}$ Analysis was done in 250 patients who received anticoagulation treatment.

Abbreviations: LMWH, low-molecular-weight heparin; NOAC, non-vitamin K-dependent new oral anticoagulant; PE, pulmonary embolism. 
Table 4 Impact of airflow limitation on VTE recurrence among PE patients with cancer

\begin{tabular}{lll}
\hline VTE recurrence & $\begin{array}{l}\text { No airflow } \\
\text { limitation } \\
(\mathbf{n}=\mathbf{2 7 5})\end{array}$ & $\begin{array}{l}\text { Airflow } \\
\text { limitation } \\
(\mathbf{n}=\mathbf{I 2 6})\end{array}$ \\
\hline $\begin{array}{l}\text { No of cases }(\%) \\
\text { Incidence rate (cases/I,000 }\end{array}$ & $3 \mathrm{I}(\mathrm{II} .3)$ & $\mathrm{I} 8(\mathrm{I} 4.3)$ \\
person-years) & 6.8 & 9.5 \\
Unadjusted HR (95\% Cl) & Reference & $\mathrm{I} .3 \mathrm{I}(0.73,2.34)$ \\
Model I & $\begin{array}{l}\text { Reference } \\
\text { Model 2 }\end{array}$ & $\mathrm{I} .20(0.64,2.26)$ \\
Model 3 & Reference & $\mathrm{I} .26(0.66,2.4 \mathrm{I})$ \\
\hline
\end{tabular}

Notes: Model I adjusted for age, sex, body mass index, and smoking (never/ever). Model 2 further adjusted for metastatic disease and recent surgery. Model 3 further adjusted for PE treatment.

Abbreviations: $\mathrm{Cl}$, confidence interval; $\mathrm{HR}$, hazard ratio; $\mathrm{PE}$, pulmonary embolism; VTE, venous thromboembolism.

(aHR 1.26 [95\% CI 0.66, 2.41]), and for PE treatment (aHR 1.29 [95\% CI 0.68, 2.45]). The hazard remained unchanged in subgroup analysis with lung cancer patients (Table S1). Furthermore, recurrent VTE was not different according to the severity of airflow limitation $(17.2 \%, 14.5 \%$, and $7.1 \%$ in $\mathrm{FEV}_{1} \geq 80 \%$ predicted, $50 \% \leq \mathrm{FEV}_{1}<80 \%$ predicted, and $\mathrm{FEV}_{1}<50 \%$ predicted, respectively) $(p=0.737)$.

\section{Discussion}

In our study of 401 cancer patients with PE, about one-third of the patients had spirometry-based airflow limitation. During the median follow-up of 9.7 months, VTE recurred in $12.2 \%$ of patients. However, coexisting airflow limitation did not increase the risk of VTE recurrence in patients with cancer.

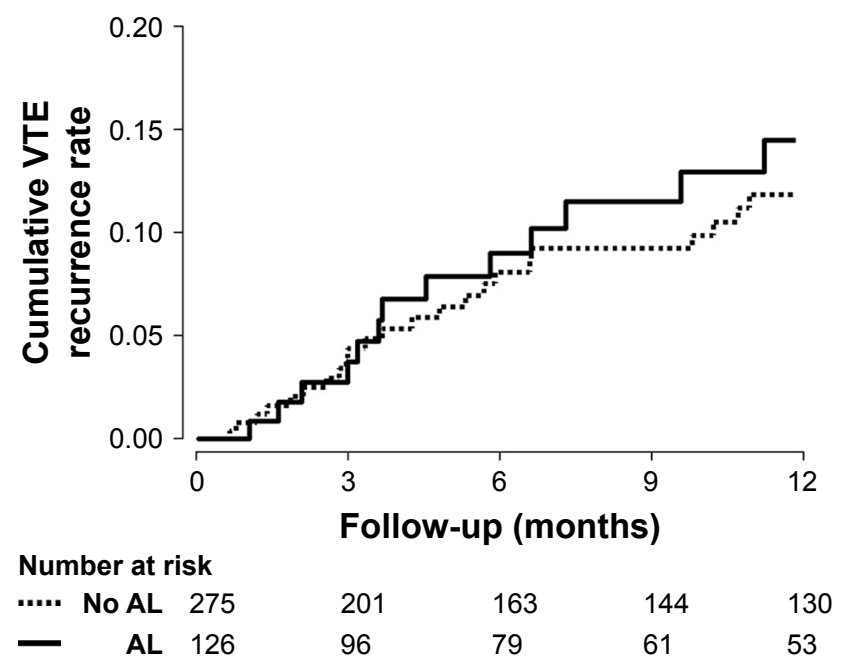

Figure 2 Cumulative VTE recurrence in cancer patients with PE according to airflow limitation.

Abbreviations: $\mathrm{AL}$, airflow limitation; $\mathrm{PE}$, pulmonary embolism; VTE, venous thromboembolism.
There have been few studies investigating VTE recurrence in COPD patients. One study was a post hoc analysis of a prospective management study in 673 hemodynamically stable PE patients. The study found that COPD was associated with increased bleeding and mortality, but not recurrent VTE over 3 months. ${ }^{20}$ Another study was performed using the RIETE registry with 28,920 symptomatic VTE patients. ${ }^{14}$ In that study, COPD patients experienced higher PE recurrence, minor bleeding, and higher rates of death by 3 months. However, recurrence of overall VTE was not different between patients with and without COPD. In both the studies, the results of the lung function tests were not available for all COPD patients, and patients could have been misclassified as COPD or non-COPD. A recent prospective cohort study of a large number of patients with long-term follow-up showed that patients with objectively measured COPD did not have an increased risk of VTE recurrence. ${ }^{15}$ However, this study did not include active cancer patients, probably to minimize confounding factors.

Our study was restricted to cancer patients to explore the association between COPD and VTE recurrence, and we also confirmed that airflow limitation was not associated with the risk of VTE recurrence in cancer patients. Several factors should be considered in interpreting this finding. First, cancer patients undergo chest CT scan more frequently, which leads to more frequent findings of incidental PE. ${ }^{21}$ Indeed, in our study, only $45.4 \%$ of cancer patients had symptomatic $\mathrm{PE}$, indicating a high proportion of incidental PE among cancer patients. This might mask the effect of airflow limitation on VTE recurrence. Second, subtherapeutic anticoagulation treatment for PE is associated with the increment of VTE recurrence. ${ }^{22}$ Approximately $38 \%$ of cancer patients did not receive anticoagulation in our study, which was at the discretion of the treating physicians. Among them, 85\% had incidentally detected PE and 57\% had PE in segmental or subsegmental pulmonary arteries. Although current guidelines recommend treating all cancer patients with $\mathrm{PE},{ }^{23,24}$ there is still debate over the use of anticoagulation in cancer patients with incidental PE. ${ }^{25}$ In addition, treatment risk (ie, bleeding) over benefits could be considered, especially in patients with asymptomatic PE in segmental or subsegmental pulmonary arteries or those with short expected survival. Nevertheless, we performed subgroup analysis in patients with anticoagulation, which revealed the same result.

There are some limitations in our study. First, because this is a retrospective cohort study in a single referral hospital with a large volume of lung cancer patients, the result of our study 
may not be generalized to patients in other settings. Second, compared with a recent study of noncancer patients, ${ }^{15}$ the follow-up duration was relatively short. This is largely attributable to high number of cancer-related deaths, which also contributed to the limited duration of anticoagulation in our study with a median duration of 4 months. However, analysis in which death was included as a competing risk of recurrence did not show a difference. Last, inclusion of patients with valid spirometry test results would have introduced selection bias. It is possible that PE patients in our study were more likely to have preexisting respiratory symptoms than $\mathrm{PE}$ patients who were not included in this study. Further prospective study with a larger and more heterogeneous cancer population is necessary to assess the generalizability of our results. Despite these limitations, our study used validated and standardized measurements to define airflow limitation and the diagnosis of PE and included cancer-related factors as well as treatment in the analyses.

\section{Conclusion}

Airflow limitation did not increase the risk of VTE recurrence in cancer patients with PE. Taken together with the result from patients without cancer, ${ }^{15}$ there seems to be no evidence at present to support different management of PE in patients with COPD. Prospective studies are necessary to confirm whether the coexistence of airflow limitation deserves attention in the management of cancer patients with PE.

\section{Abbreviations}

aHR, adjusted hazard ratio; CI, confidence interval; CT, computed tomography; DVT, deep vein thrombosis; $\mathrm{FEV}_{1}$, forced expiratory volume in 1 second; FVC, forced vital capacity; HR, hazard ratio; IQR, interquartile range; $\mathrm{PE}$, pulmonary embolism; RIETE, Registro Informatizado de la Enfermedad Thomboembolica venosa; VTE, venous thromboembolism.

\section{Disclosure}

The authors report no conflicts of interest in this work.

\section{References}

1. Heit JA. Epidemiology of venous thromboembolism. Nat Rev Cardiol. 2015;12(8):464-474.

2. Goldhaber SZ, Visani L, De Rosa M. Acute pulmonary embolism: clinical outcomes in the International Cooperative Pulmonary Embolism Registry (ICOPER). Lancet. 1999;353(9162):1386-1389.

3. Becattini C, Agnelli G, Pesavento R, et al. Incidence of chronic thromboembolic pulmonary hypertension after a first episode of pulmonary embolism. Chest. 2006;130(1):172-175.
4. Heit JA, Mohr DN, Silverstein MD, Petterson TM, O'Fallon WM, Melton LJ 3rd. Predictors of recurrence after deep vein thrombosis and pulmonary embolism: a population-based cohort study. Arch Intern Med. 2000;160(6):761-768.

5. Carrier M, Le Gal G, Wells PS, Rodger MA. Systematic review: casefatality rates of recurrent venous thromboembolism and major bleeding events among patients treated for venous thromboembolism. Ann Intern Med. 2010;152(9):578-589.

6. Konstantinides SV, Torbicki A, Agnelli G, et al; Task Force for the Diagnosis and Management of Acute Pulmonary Embolism of the European Society of Cardiology (ESC). 2014 ESC guidelines on the diagnosis and management of acute pulmonary embolism. Eur Heart J. 2014;35(43): 3033-3069, 3069a-3069k.

7. Jiménez D, Aujesky D, Moores L, et al; RIETE Investigators. Simplification of the pulmonary embolism severity index for prognostication in patients with acute symptomatic pulmonary embolism. Arch Intern Med. 2010;170(15):1383-1389.

8. Sidney S, Sorel M, Quesenberry CP Jr, DeLuise C, Lanes S, Eisner MD. COPD and incident cardiovascular disease hospitalizations and mortality: Kaiser Permanente Medical Care Program. Chest. 2005; 128(4):2068-2075.

9. Curkendall SM, DeLuise C, Jones JK, et al. Cardiovascular disease in patients with chronic obstructive pulmonary disease, Saskatchewan Canada cardiovascular disease in COPD patients. Ann Epidemiol. 2006;16(1):63-70.

10. Schneider C, Bothner U, Jick SS, Meier CR. Chronic obstructive pulmonary disease and the risk of cardiovascular diseases. Eur J Epidemiol. 2010;25(4):253-260.

11. Chen WJ, Lin CC, Lin CY, et al. Pulmonary embolism in chronic obstructive pulmonary disease: a population-based cohort study. COPD. 2014;11(4):438-443.

12. Morgan AD, Herrett E, De Stavola BL, Smeeth L, Quint JK. COPD disease severity and the risk of venous thromboembolic events: a matched case-control study. Int J Chron Obstruct Pulmon Dis. 2016;11: 899-908.

13. Børvik T, Brækkan SK, Enga K, et al. COPD and risk of venous thromboembolism and mortality in a general population. Eur Respir J. 2016;47(2):473-481.

14. Bertoletti L, Quenet S, Mismetti P, et al; RIETE Investigators. Clinical presentation and outcome of venous thromboembolism in COPD. Eur Respir J. 2012;39(4):862-868.

15. Le Mao R, Tromeur C, Bazire A, et al. Risk of recurrent venous thromboembolism in COPD patients: results from a prospective cohort study. Eur Respir J. 2017;50(1).

16. Hutten BA, Prins MH, Gent M, Ginsberg J, Tijssen JG, Büller HR. Incidence of recurrent thromboembolic and bleeding complications among patients with venous thromboembolism in relation to both malignancy and achieved international normalized ratio: a retrospective analysis. J Clin Oncol. 2000;18(17):3078-3083.

17. Prandoni $P$, Lensing AW, Piccioli A, et al. Recurrent venous thromboembolism and bleeding complications during anticoagulant treatment in patients with cancer and venous thrombosis. Blood. 2002;100(10):3484-3488.

18. Gussoni G, Frasson S, La Regina M, Di Micco P, Monreal M; RIETE Investigators. Three-month mortality rate and clinical predictors in patients with venous thromboembolism and cancer. Findings from the RIETE registry. Thromb Res. 2013;131(1):24-30.

19. Miller MR, Hankinson J, Brusasco V, et al; ATS/ERS Task Force. Standardisation of spirometry. Eur Respir J. 2005;26(2):319-338.

20. Nijkeuter M, Söhne M, Tick LW, et al; Christopher Study Investigators. The natural course of hemodynamically stable pulmonary embolism: clinical outcome and risk factors in a large prospective cohort study. Chest. 2007;131(2):517-523.

21. Dentali F, Ageno W, Becattini C, et al. Prevalence and clinical history of incidental, asymptomatic pulmonary embolism: a meta-analysis. Thromb Res. 2010;125(6):518-522. 
22. Heit JA, Lahr BD, Petterson TM, Bailey KR, Ashrani AA, Melton LJ 3rd. Heparin and warfarin anticoagulation intensity as predictors of recurrence after deep vein thrombosis or pulmonary embolism: a populationbased cohort study. Blood. 2011;118(18):4992-4999.

23. Lyman GH, Khorana AA, Kuderer NM, et al; American Society of Clinical Oncology Clinical Practice. Venous thromboembolism prophylaxis and treatment in patients with cancer: American Society of Clinical Oncology clinical practice guideline update. J Clin Oncol. 2013;31(17):2189-2204.
24. Kearon C, Akl EA, Comerota AJ, et al. Antithrombotic therapy for VTE disease: Antithrombotic Therapy and Prevention of Thrombosis, 9th ed: American College of Chest Physicians Evidence-Based Clinical Practice Guidelines. Chest. 2012;141(2 Suppl):e419S-e496S.

25. Peris M, Jiménez D, Maestre A, et al; RIETE Investigators. Outcome during and after anticoagulant therapy in cancer patients with incidentally found pulmonary embolism. Eur Respir J. 2016;48(5):1360-1368. 


\section{Supplementary material}

Table SI Impact of airflow limitation on VTE recurrence among PE patients with lung cancer

\begin{tabular}{lll}
\hline VTE recurrence & $\begin{array}{l}\text { No airflow } \\
\text { limitation } \\
(\mathbf{n}=\mathrm{II} \mathbf{8})\end{array}$ & $\begin{array}{l}\text { Airflow } \\
\text { limitation } \\
(\mathbf{n}=\mathbf{8 2})\end{array}$ \\
\hline $\begin{array}{l}\text { No of cases }(\%) \\
\text { Incidence rate (cases/I,000 }\end{array}$ & $\mathrm{I} 3(\mathrm{II} .0)$ & $\mathrm{I} 3(\mathrm{I} 5.9)$ \\
person-years) & 6.2 & $\mathrm{II} .7$ \\
Unadjusted HR $(95 \% \mathrm{Cl})$ & Reference & $\mathrm{I} .70(0.78,3.69)$ \\
Model I & $\begin{array}{l}\text { Reference } \\
\text { Model 2 }\end{array}$ & $\mathrm{I} .78(0.74,4.30)$ \\
Model 3 & Reference & $\mathrm{I} .74(0.70,4.33)$ \\
\hline Reference & $\mathrm{I} .72(0.70,4.22)$ \\
\hline
\end{tabular}

Notes: Model I adjusted for age, sex, body mass index, and smoking (never/ever). Model 2 further adjusted for metastatic disease and recent surgery. Model 3 further adjusted for PE treatment.

Abbreviations: $\mathrm{Cl}$, confidence interval; $\mathrm{HR}$, hazard ratio; $\mathrm{PE}$, pulmonary embolism; VTE, venous thromboembolism.

\section{Publish your work in this journal}

The International Journal of COPD is an international, peer-reviewed journal of therapeutics and pharmacology focusing on concise rapid reporting of clinical studies and reviews in COPD. Special focus is given to the pathophysiological processes underlying the disease, intervention programs, patient focused education, and self management protocols.

\section{Dovepress}

This journal is indexed on PubMed Central, MedLine and CAS. The manuscript management system is completely online and includes a very quick and fair peer-review system, which is all easy to use. Visit $\mathrm{http}: / / \mathrm{www}$.dovepress.com/testimonials.php to read real quotes from published authors.

Submit your manuscript here: http://www.dovepress.com/international-journal-of-chronic-obstructive-pulmonary-disease-journal 